\title{
Challenges and Directions in Knowledge Asset Trading
}

\author{
Dimitris Apostolou ${ }^{1}$, Gregory Mentzas², Andreas Abecker ${ }^{3}$, \\ Wolf-Christian Eickhoff ${ }^{4}$, Wolfgang Maas ${ }^{4}$, Panos Georgolios ${ }^{2}$, Kostas Kafentzis ${ }^{2}$, \\ and Sophia Kyriakopoulou ${ }^{1}$ \\ ${ }^{1}$ Planet Ernst \& Young, Apollon Tower, 64 Louise Riencourt Str., 11523 Athens, Greece \\ dapost@planetey.com \\ ${ }^{2}$ Department of Electrical and Computer Engineering, National Technical University of \\ Athens, 10682 Greece \\ \{gmentzas, pgeorgol, kkafe\}@softlab.ntua.gr \\ ${ }^{3}$ DFKI GmbH, Erwin-Schroedinger-Strasse, D-67608 Kaiserslautern, \\ aabecker@dfki.uni-kl.de \\ ${ }^{4}$ Institute for Media and Communications Management, University of St.Gallen, \\ Blumenbergplatz 9, CH-9000 St.Gallen \\ wolf-christian.eickhoff@unisg.ch
}

\begin{abstract}
This paper addresses the area that is at the intersection of Knowledge Management and Electronic Commerce. This area refers to the exchange and trade of explicit and implicit knowledge at an inter-organisational level. Electronic knowledge marketplaces are currently emerging to address the opportunities and risks found in the purchase and selling of knowledge at the business-to-business (B2B) environment, the need for supporting long-lasting relationships of knowledge exchange and the requirement for facilitating virtual community contexts where knowledge seekers can find suitable knowledge providers and knowledge providers can advertise and sell their available knowledge. The paper describes the business challenges associated with the design of Internet-based knowledge marketplace. INKASS, a European IST project, has stimulated this work and has provided real-life verification on the arguments raised and on the positions adopted herein.
\end{abstract}

\section{Introduction}

Organisations are in the midst of two significant transformations. The first is the positioning of knowledge centre stage as a valuable resource and a driver of wealth creation. The second is the impact of the Internet, leading to the evolution of business into e-business. Until recently these developments were considered in isolation (Gartner, 2000). But there are connections, and these are becoming increasingly apparent. Knowledge is an asset that can be re-packaged into knowledge-based products and services. The Internet provides an effective vehicle for marketing and delivering knowledge. The new term knowledge trading captures the convergence of these two strands.

The first focus of many knowledge initiatives in organisations is one of identifying and sharing existing knowledge more widely: "if only we knew what we know". Better management of this knowledge is used to improve business processes, increase 
productivity, and reduce new product development times. Beyond these initial benefits, organisations then turn to ways in which knowledge management can be used to improve their external performance. Much internally generated knowledge is applicable externally and can be converted into viable knowledge-based products and services. As in many types of business, network connectivity, and in particular extended connections offered by the Internet, offers many advantages for a knowledge business. It reduces transaction costs, extends market reach and allows round-the-clock trading.

Already the idea of knowledge trading is an exciting topic with manifold implications in both technological areas and business engineering. Early adopters of the knowledge trading idea are already working towards this goal, some of them dealing with some facets of the overall scenario, maybe unaware of the bigger picture behind, like researchers building Expert Finder Systems which are mainly thinking about significant technical solutions for the matchmaking between information needs and expert competency profiles, but paying less attention to other business-related topics around, like market mechanisms, revenue models, etc., which are required to run a business. Existing approaches:

- neither take into account the fact that knowledge is not just a book which can be described and retrieved with a simple keyword retrieval, but has manifold complex context and content features which determine its applicability and usefulness in a given situation;

- nor take into account that the real power of electronic marketplaces lies not in copying ways of working known from traditional business (like book selling with a catalogue and a simple, sequential seller-intermediary-buyer relationship), but in exploiting the strength of manifold synchronous and asynchronous communication and community-building means, which is of utmost importance when dealing which such a sensible good as knowledge;

- nor take into account that setting up a Web-portal is far from designing sustainable business which means thinking about customer relationship, advanced revenue models, appropriate pricing mechanisms for different kinds of knowledge, etc.

This paper aims to identify the core elements associated with knowledge trading. The paper is largely based on the research and early findings which have taken place at the framework of the European Community IST project [Intelligent Knowledge Asset Sharing and Trading (INKASS, 2000)] that is going to design and implement knowledge trading tools, and develop and validate business models for electronic knowledge marketplace. In the following sections we introduce the concept of a knowledge marketplace and we discuss its economics based on the overall economics of electronic marketplaces and the special characteristics that knowledge assets possess when considered as tradable products. We present how these ideas apply in the design of a knowledge marketplace for a consultancy and we conclude by providing key challenges and issues that need to be considered in similar initiatives. 


\section{The Emergence of Knowledge Marketplaces}

A knowledge market is a place where knowledge is traded. Within organizations, the need for continuous access to knowledge has spurred the development of various knowledge initiatives. Davenport and Prusak (1998) suggest that knowledge movement within the organisations is powered by market forces similar to those that animate markets for other, more tangible goods. Like markets for goods and services, the knowledge market has buyers, sellers, and brokers, as well as market pricing and exchange mechanisms, even though money is rarely the form of payment. Outside the organization, similar knowledge exchange mechanisms exist in knowledge networks, whether these are professional societies or special interest groups in informal networks. Knowledge is also exchanged as part of everyday business conversation. The more aware individuals are of the value of the knowledge they possess, the more care they will take in giving it away freely outside of their close network or a formal trading relationship. The growing importance of knowledge indicates that the time is right for the creation of mechanisms to improve the flow of knowledge and to increase the efficiency of knowledge exchange and trading. The pervasiveness of the Internet has already started to shift existing knowledge markets into the Web. Examples include (Skyrme, 2001):

- Intellectual property trading. Copyright material, patents and designs are increasingly traded online, widening creator access to a broader market base. Trading sites can also serve as rights clearing houses.

- Recruitment agencies. Many types of recruitment, such as computer contracting, are fast shifting into online mode. The pool of job seekers and recruiters is larger. Computerized testing and profile-to-job matching helps both parties more quickly find mutually beneficial matches. Portal sites such as Carrermosaic.com give hints on writing CV's, links to recruitment fairs etc.

- Management consultancies. Their business is knowledge, but they are increasingly packaging it, both for internal use (on their intranets and knowledge bases) and externally, such as Arthur Andersen's Global Best Practices and Ernst \& Young's Ernie.

- Research companies. Market and industry researchers, such as Nielsen and The Welding Institute now deliver much of their material over the Web or transfer it to clients' intranets.

Other developments are also influencing the creation of online knowledge markets. One is the growth of the Internet as a vehicle for e-commerce and knowledge exchange. Many of the commerce models of e-marketplaces, such as auctions, can be adapted to the marketing of knowledge. Business-to-business exchanges, in particular, offer significant potential for increasing the efficiency of buying and selling. The popularity of online communities demonstrates the high interest in seeking and sharing knowledge with like-minded people. Here the same factors that apply in internal knowledge markets-reciprocity, repute and altruism (Prusak and Davenport, 1998)-are also important. But many knowledgeable people who are not active in these communities may be encouraged to do so, too, if they were compensated financially for their time and expertise. 
Apart from buyers and sellers, markets need a market-making mechanism to work. As a minimum an online website will need facilities to capture and process details of needs and offers. It may add intelligence that includes matchmaking capabilities and a set of business rules. These rules may filter out specific matches, based on personal preferences of buyer and seller, or they may include rules for dynamic pricing to maximize revenues. If the market is a full trading hub, order processing and account management facilities will be needed. They may even host various delivery mechanisms, including online knowledge repositories and communities. In return for providing these facilities, the market maker will seek revenues from one or more sources, such as commissions from buyers and/or sellers, advertisers, sponsors, or from affiliate fees for successful referrals to complementary websites.

\section{The Economics of E-knowledge Marketplaces}

\subsection{The Economics of E-marketplaces}

Electronic marketplaces can be said to represent a new wave in the e-commerce propagation and extending the Business and Consumer combinations (B2C, C2B and C2C) aiming primarily at the Business-to-Business (B2B) area. E-marketplaces can be defined as interactive business communities providing a central market space where multiple buyers and suppliers can engage in e-commerce and/or other e-business activities (Bruun et. al., 2002). They present structures for commercial exchange, consolidating supply bases and creating sales channels. Their primary aim is to increase market efficiency by tightening and automating the relationship between supplier and buyer. Existing e-marketplaces allow participants to access various mechanisms to buy and sell almost anything, from services to direct materials.

The products and services offered on e-marketplaces may either be industryspecific or horizontal across many applications. A number of classification schemata exist in the literature for e-marketplaces (Kaplan and Sawhney, 2000), (Dou and Chou, 2002), (BuyIT, 2002). Overall we may distinguish between three primary emarketplace models:

- Direct or Private B2B e-marketplaces. These are one-to-many models that reflect a company developing their own e-marketplace to support their own customers and suppliers.

- Coalitions or consortium e-marketplaces. These models reflect a many-to-many model in which major industry players come together to aggregate their buy-side and supplier-side leverage to increase operational efficiencies and leverage buying power around an industry supply chain.

- Independent e-marketplaces. This is a many-to-many model, typically hosted by a neutral intermediary providing Net Market Maker services, such as aggregation, transaction services to participants.

These three types of e-marketplaces vary in different characteristics, such as member structure, value, business model, or financing and business impact (Table 1). 
Table 1. Characteristics of e-Marketplaces (adopted from BuyIT, 2002)

\begin{tabular}{|c|c|c|c|}
\hline & Independent & Coalitions/ Consortium & Direct \\
\hline Member & Many-to-many & Few-to-Many & One-to-Few/Many \\
\hline Structure & Open membership & $\begin{array}{l}\text { Anchored by a number } \\
\text { of companies } \\
\text { Open membership on the } \\
\text { "many" side }\end{array}$ & $\begin{array}{l}\text { Anchored by sponsoring } \\
\text { company }\end{array}$ \\
\hline Value & $\begin{array}{l}\text { Market efficiency } \\
\text { Liquidity } \\
\text { Transparency } \\
\text { Shared benefits }\end{array}$ & $\begin{array}{l}\text { Market efficiency } \\
\text { Liquidity } \\
\text { Transparency } \\
\text { Shared benefits }\end{array}$ & $\begin{array}{l}\text { Deep collaboration } \\
\text { Value chain optimisation } \\
\text { Speed and flexibility } \\
\text { Privacy and control } \\
\text { Retention of all benefits } \\
\text { Customer satisfaction } \\
\text { Service/process excellence }\end{array}$ \\
\hline $\begin{array}{l}\text { Business } \\
\text { Model }\end{array}$ & $\begin{array}{l}\text { Revenue based on } \\
\text { transaction } \% \text {, } \\
\text { services, } \\
\text { membership, } \\
\text { advertising, etc. }\end{array}$ & $\begin{array}{l}\text { Revenue based on } \\
\text { transaction \%, services, } \\
\text { membership, advertising, } \\
\text { etc. }\end{array}$ & $\begin{array}{l}\text { Revenue based on benefit } \\
\text { sharing, margin sharing, speed } \\
\text { of innovation, service fees }\end{array}$ \\
\hline Financing & Net Market Maker & Core members & Anchor members \\
\hline $\begin{array}{l}\text { Business } \\
\text { Impact }\end{array}$ & $\begin{array}{l}\text { Dis- } \\
\text { intermediation, } \\
\text { Re-intermediation }\end{array}$ & $\begin{array}{l}\text { Dis-intermediation, } \\
\text { Re-intermediation }\end{array}$ & $\begin{array}{l}\text { Expand competitive advantage } \\
\text { Control value chain }\end{array}$ \\
\hline
\end{tabular}

\subsection{The Economics of Knowledge}

The positioning of knowledge assets centre stage in B2B exchanges is in line with the recent trend in the strategic management that positions knowledge as the primary resource (Drucker, 1994), that is the primary assumption in the Knowledge-BasedView of the firm (Eisenhardt and Santos, 2001). The specific knowledge base, the ability to make use of the available knowledge determines the competitiveness of organisations in the emerging knowledge society (Franke, 2000).

Knowledge assets are different from other firm resources; see e.g. Glazer (1991) and Day and Wendler (1998). They are not easily divisible or appropriable. This means that the same information and knowledge can be used by different economic entities at the same time. Moreover, knowledge assets are not inherently scarce (although they are often time-sensitive). This implies that they are not depleatable.

Knowledge assets are essentially regenerative. This means that new relevant knowledge may emerge from a knowledge-intensive business process as additional output besides products and services. They may not exhibit decreasing returns to use, but will often increase in value the more they are used. This characteristic is of crucial importance for senior management; see e.g. den Hartigh and Langerak (2001). Most assets are subject to diminishing returns, but not knowledge. The bulk of the fixed cost in knowledge products usually lies in creation rather than in manufacturing or distribution. Once knowledge has been created, the initial development cost can be spread across rising volumes.

Network effects can emerge as knowledge assets are used by more and more people. These knowledge-users can simultaneously benefit from knowledge and increase its value as they add to, adapt, and enrich the knowledge base. In traditional 
industrial economics, assets decline in value as more people use them. By contrast, knowledge assets can grow in value, as they become a standard on which others can build.

Finding appropriate prices for knowledge assets is a challenging task (O'Hara and Shadbolt, 2001). As knowledge assets have an intangible character, there are certain specialities for the price-finding which are derived from its general characteristics:

- Because of the lack of visible capability characteristics, the price can be viewed as an indirect criterion for rating the quality of the knowledge asset.

- A direct comparison of prices is usually difficult without actual utilization of the knowledge asset.

- Due to the intangible character of the knowledge asset it is difficult to find out in advance about the customers' willingness to pay a certain price for an asset.

In the following we provide an overview of the factors that set value on knowledge, when considering knowledge assets as tradable goods.

\section{Context of knowledge}

One central problem lies in the fact that knowledge is by definition highly contextdependent, whereas all explicit representations (at the seller side) will necessarily decontextualise it to some extent. Furthermore, in an electronic marketplace, such representations should also express aspects like knowledge quality and knowledge actuality, which can hardly be dealt with in a generally applicable manner, but must be considered separately for different types of knowledge products and knowledge requests. Knowledge has manifold complex context and content features, which determine its applicability and usefulness in a given situation.

Affiliation and branding

Affiliation is also a significant factor to be considered when setting a price on knowledge. Knowledge purchases are immensely affected by the degree of affiliation between the buyer and the seller. Because of the criticality, sensitivity and high customisation of knowledge products and services, the need for trust and established relationships increase proportionally. Branding plays also a significant role, because it associates a purchase with a certain level of quality of service, guarantee and aftersales support.

Refined and customised knowledge

The value of knowledge increases as it is refined, improved and formatted ready to be used. Users will value most knowledge that is relevant to them and provided ready to be used by them. Generalised knowledge will be priced toward the lower end of the scale, while customised knowledge on a critical purchasing decision, for example, that combines the latest data with analysis from experts will command a higher value. Timing of knowledge

Timing is also an important ingredient of the value of a knowledge offering: knowledge is most valuable at the exact moment that is needed for critical business requirements. Knowledge is also valued by the timing that it is received in advance of the competition. As knowledge product and services are offered on the marketplace, the value of these services will be determined by the timeliness and impact of this knowledge on the person purchasing this knowledge.

Tacit knowledge

A powerful combination is that of tacit and explicit knowledge. While codified generic knowledge may have relatively low value, the addition of human judgment and experience can considerably enhance value. Capturing the information is the first 
step, followed by rationalizing the data so that it can be shared by appropriate people. It is the expert nevertheless that can add his/her experience and can assist in putting knowledge in context or solving a particular problem.

Aggregated knowledge

Aggregated knowledge is often worth more than the sum of the parts (Skyrme, 2001). The buyer will benefit from one-stop-shop, because it reduces the time and effort needed to collect information form multiple sources. Expertly collated and edited information can eliminate overlaps while highlighting contrasts. The richness and depth in one place aids understanding and offers new insights.

Quality of knowledge

The quality of knowledge products can be related to different criteria, like accuracy, reliability, presentation, timeliness, completeness, highlighting of main issues, relevancy and usable format (Rolph and Bartram 1994). In general there are two different perspectives to consider when talking about quality of information: on the one hand an individual or a company creates knowledge-based products and on the other hand they are distributed on a marketplace to other individuals or organisations. This leads to a constructivist and a receptive view on the quality of the product. For both views it is necessary to develop methods that ensure that only high-quality products are used in problem solving processes (Nohr and Roos, 2001).

\begin{tabular}{ll}
\hline Constructivist & The constructivist quality includes all measures that are taken to \\
Quality & $\begin{array}{l}\text { ensure quality assurance during the production and distribution } \\
\text { processes of knowledge products. Thereby attention is paid to the } \\
\text { quality of the process, besides of the quality of the result }\end{array}$ \\
Receptive & The receptive quality refers to measures concerning the evaluation \\
Quality & and rating of external products. It is most commonly related to the \\
& sources of information or the creator, because the knowledge asset \\
& itself is not available for direct evaluation.
\end{tabular}

Compared to other products, knowledge products have the special characteristic that they cannot be previewed and tested before the purchase. Though the quality can generally not completely be experienced beforehand. Nevertheless, there need to be some indicators to assess it in advance. Concerning the receptive quality there are five general possibilities to improve customer's trust for the product: (1) Trust in the source of knowledge due to earlier experiences; (2) Quality assessment by trustedthird parties; (3) Quality assessment by the users or customers; (4) Trial versions; (5) Description by Meta-Information.

\subsection{The Right Model for Knowledge Marketplaces}

Evans and Wurster (2000) group potential benefits of e-marketplaces in three "dimensions of advantage": (i) reach, which means how many customers a business can connect with and how many products it can offer to those customers; (ii) richness, is the depth and detail of information that the business can give the customer, as well as the depth and detail of information; and (iii) affiliation with participants, especially buyers. By affiliating with customer a net market maker can make money by providing value-added services such as advice. 
The traditional economics of information suggest that rich information requires proximity and dedicated channels, imposing thereby limits on the reach potential of the same information. Evans and Wurster (2000) suggest that our economy is on the verge of a new era characterised by the gradual removal of the trade-off between the richness and the reach of information. The emergence of independent e-marketplaces is a proof of the aforementioned analysis. Independent marketplaces have emerged with the objective to capitalise on the increased reach capability of the Internet, coupled with sophisticated Information Technology applications able to manage and process rich information.

Nevertheless many analysts (Bruun, et.al., 2002); (Gartner, 2001); (Davenport et. al. 2001) believe that independent e-marketplaces have had difficulty achieving both high levels of reach and richness, even in non knowledge-intensive sectors. This market reality combined with the special characteristics of knowledge assets as tradable products render the direct or private marketplace type as the prominent one, because it offers the: (a) required deep collaboration between buyer and seller; (b) speed and flexibility required for timely provision of critical, sensitive knowledge products; (c) privacy and control needed to create trusted relationships; and (d) quality of service that is a prerequisite for customer satisfaction.

\section{The INKASS Project Approach}

The INKASS project tries to overcome some of these challenges by spending due diligence to both technological and methodological developments, investigating issues like creation of trust and customer satisfaction.

Figure 1 gives an overview of the functional architecture to be developed. For building such a platform and validating it in realistic case studies, the INKASS approach is guided by the following principles:

- Integrate e-commerce with knowledge management software technology: The decision the INKASS consortium has taken is to build upon Intershop's Enfinity, which is a backbone E-Commerce platform, and Empolis' Orenge, which is an ECommerce middleware solution for intelligent retrieval and assistance.

- At the technological side, focus on the critical questions which distinguish knowledge trading from other E-Commerce areas; we see crucial points (i) in a powerful, knowledge-based matchmaking mechanism comparing offers and demand; (ii) in flexible, intuitive interfaces and intelligent assistance helping users to express their demands and interactively search for appropriate offers; and (iii) in elaborated networking and community-building facilities to exploit the power of customer groups exchanging and further developing knowledge in direct communications, assessing the value of products, etc.

- At the operational side, focus on how to cost-effectively use the platform for the novel problem of trading knowledge. In order to do this, at least the following elements must be worked out:

- The very basic ontological foundations for the utilization of E-Commerce systems for knowledge trading, plus cost-effective methods for up-front knowledge engineering. 
- An overall system design (eg. business engineering) and configuration of existing mechanisms (eg. different pricing mechanisms) which take into account the particularities of knowledge trading.

- Appropriate business models, roles, processes, and revenue models for installing and running knowledge trading platforms.

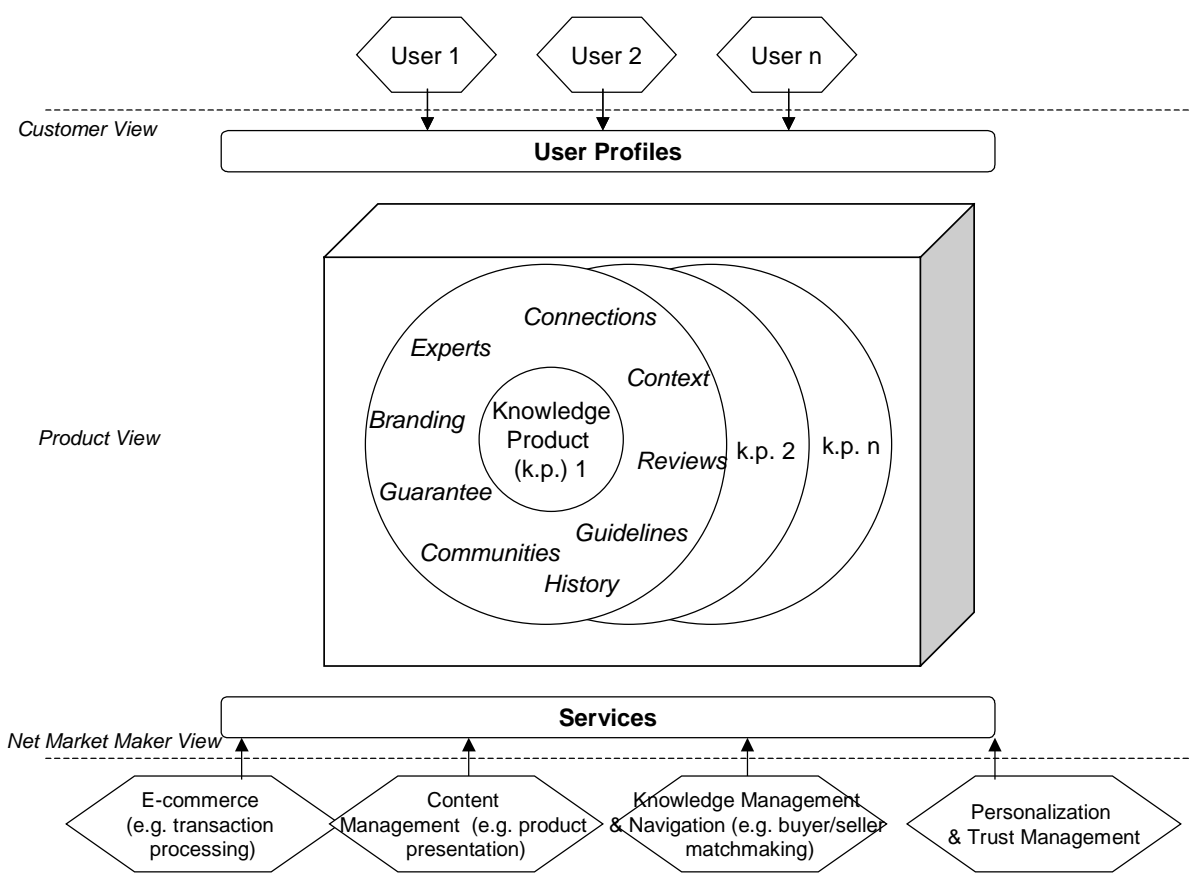

Fig. 1. The INKASS Functional Architecture for Knowledge Trading

INKASS will pilot knowledge trading in the Business Management and Engineering areas, with the participation of three knowledge-intensive organisations: The Welding Institute (a research and technology organisation), Planet Ernst \& Young (a consultancy), and the Athens Chamber of Commerce and Industry.

\section{Designing a Knowledge Marketplace for a Consultancy}

Planet Ernst \& Young (PLEY) is a multinational consulting firm providing management and engineering consulting services in southeast Europe? PLEY provides a wide spectrum of consulting services mainly to sizable private and public sector organisations. PLEY's consulting practice has focused on developing and expanding their relationship with key large organizations in the region. There is plenty of opportunity within this customer-base and PLEY's full-service capabilities

1 The company was formed following the merger of PLANET S. A. and the Southeast Europe Management Consulting network of Ernst \& Young. 
to enable them to continually meet the needs of this type of client. Despite the recent slow down in the management consulting services at the global level, PLEY has seen a growth of $20 \%$ per year over the past five years.

\subsection{Strategic Orientation}

When PLEY started thinking of commercially exploiting knowledge products and services over the Internet, it was faced with two broad choices:

- Utilize on-line knowledge trading to expand to new market segments, both in geographic and in company size terms, similarly to the original thinking behind Ernie, the on-line consultant launched in 1997 by Ernst \& Young International (Whittle, 1997).

- Utilize the knowledge marketplace as a private exchange to offer to its major clients a knowledge resource, and a secure channel for working online and using dedicated business tools.

The latter choice of a private knowledge marketplace was deemed more appropriate because it was considered more feasible from a technical perspective (because integration issues with existing processes and roles are easier to solve), and more meaningful from a business perspective because (a) it allows for better client relationship management; (b) it can lead to supply chain efficiency by allowing clients, partners, subcontractors and PLEY to share and develop knowledge (primarily on a project basis); and (c) it can lead to new knowledge creation because of the focused and close interaction between PLEY and its clients. PLEY recognizes that some type of knowledge can be delivered efficiently on-line, while other require person-to-person contact. The private exchange model allows for offering a broader array of service delivery.

\subsection{The Knowledge Offerings}

The knowledge offerings that PLEY is putting on-line cover the core services (Strategy and Policy Development, Programme and Change Management, Process Improvement, Knowledge Management, Financial Management, Human Resources Management, Supply Chain Management, Marketing \& Communications, Technology and IT Consulting) as these are provided to the major industries (Financial Institutions, Comm. Media \& Entertainment, Commerce and Tourism, Transport, Energy and Utilities, Government and Health Care).

Each service is represented by a collection of information that include: methodologies, assessment or analysis tools, expert profiles, links to related documents and sources (internal/external), case studies and related training material. This core package is accompanied by metadata that aim to assist the user in finding and customizing content. These include: meta-information (taxonomical data, summaries, abstracts), historical data (identity, modification history), validation data (performed by internal experts), as well as marketing and pricing data.

Contextualisation of knowledge is accomplished by two mechanisms. First, content is filtered according to the user profile (e.g. if the user is working for a specific industry, then only relevant segments that have been classified accordingly are represented). Second, by offering a range of "self-service" tools (such as 
methodological components) that can help the user put prior knowledge in context. Nevertheless, irreplaceable human intelligence is accounted for by providing the option of providing expert advice, as part of the service offering.

\subsection{The Trading Mechanisms}

The traditional subscription scheme is retained mainly to serve the firm's major clients, but additional pricing mechanisms, appropriate for the one-to-many trading model, are considered. These include:

- Pay-per-document, to allow ad hoc users to buy just the items they need. The document-based knowledge product may be sold (a) at a fixed price or/and (b) by biding that includes the setting up of an initial asking price, and controlling the price fluctuation based on the number of sales and the inactive time intervals.

- Negotiation subsystem, to allow users to develop a request for the purchase of more complex products and to reach to an agreement for provision of a knowledge product (that perhaps involves buying expert consulting time). If a buyer cannot find the exact items or at the price they wish to pay, they may initiate a Request for Quote (RFQ). In composing the details of the RFQ, the buyer can elect to allow certain fields within the description of the product to be able to be modified by the seller. The RFQ can be used to negotiate a long-term contract, in which the prices, qualities and dates are to be agreed between the two parties.

\subsection{Operational Considerations}

In addition to the external market challenges facing PLEY there are significant internal issues that need to be addressed. There is a need to determine how to make the connection from the user to the expert. To this end the existing internal knowledge management infrastructure is exploited: Internal Knowledge Managers, who are already responsible for managing and updating knowledge at the service level, are also assigned the additional responsibility to manage the content that is available externally and to make sure that the user of the system succeeds in contacting the appropriate expert.

The quality of the knowledge offerings on the marketplace is of critical importance. The ways these offerings are used by the firm's clients can have a significant impact on the business, and care must be taken to ensure knowledge is not being misused. Quality is ensured by the experience and expertise of the Knowledge Providers. Additionally there are plans for receiving direct feedback from customers to monitor client satisfaction. The "closed group" nature of the marketplace allows for consultants to have a close relationship with the clients and to trigger feedback. Furthermore it allows for ensuring that clients are using the system properly and understand how to take advantage of its features. 


\section{Directions for Designing Knowledge Marketplaces}

The personal nature of much knowledge means that human and social factors loom large in many areas of trading and exchanging knowledge. When professionals and managers seek advice, their first port of call is usually someone in their knowledge network, for example a work colleague or a peer in another organization. If their knowledge needs are greater or not easily obtained through their network, they tend to go first to people and suppliers they already know and trust. Established relationships count for a lot. Much existing buying of knowledge, especially that which is more people-based, takes place through established supply chains.

Traditional marketplaces on the contrary are more dynamic. They bring together buyers and sellers who do not necessarily know of each other. They allow participants to compare what's on offer and learn more about what products and services are available. They engender competition and innovation. They also foster cooperation in that suppliers get together to address common concerns. In the real world, trade exhibitions and competitive tendering for services are situations that show some of these characteristics. Conferences are other occasions where professionals can top up their knowledge for a fee. Between such events, professional workers seeking knowledge have to rely on their network or other means, which do not necessarily get them the best knowledge at the keenest price.

The concept of interoperable knowledge hubs evolved as a trade-off, a compromise between the prominent traditional model of conducting knowledge business in closed, private networks, such as the PLEY case, and the market efficiency, liquidity and transparency of broad, open, public networks. During analysis of the knowledge requirements of the INKASS pilot users and their business partners, an environment that would enable their business partners to have easy and real-time access to up to date information and custom-made solutions to their inquiries was acknowledged as a significant advantage. The business partners could be kept aware of the latest knowledge in their domain, gain a rich representation and good understanding of knowledge products on offer, query about costs and even decide to consult an expert on-line. Furthermore, the possibility to reconstruct and contextualise the knowledge offering taking into account the specific needs of the client was deemed essential.

However, most business partners confessed that, in the usual case, a certain knowledge provider, which they mainly co-operate with, does not have all the expertise required to address their needs. These needs may go beyond the specialist capabilities of any single business partner, or in fact, any private knowledge marketplace. To cater to broader knowledge requirements, marketplaces may link to each other creating networks based on the exchange and trading of knowledge. Knowledge networks can be formed in two general ways:

- through an infomediary business body that will manage the information flow across the marketplaces (resembling the centralised or star network model), or

- through a "knowledge hub", that connects one marketplace with one or more other marketplaces (resembling the distributed or hub network model).

Either model results in linking effectively and extending the knowledge offerings without giving up "control" of the buyer. The ability of marketplaces to interoperate extends the idea of liquidity and network effect by joining more buyers with more suppliers, but it does not sacrifice the ability of each knowledge marketplace to be highly specific to the supply-chain node or target buyer group it serves. 

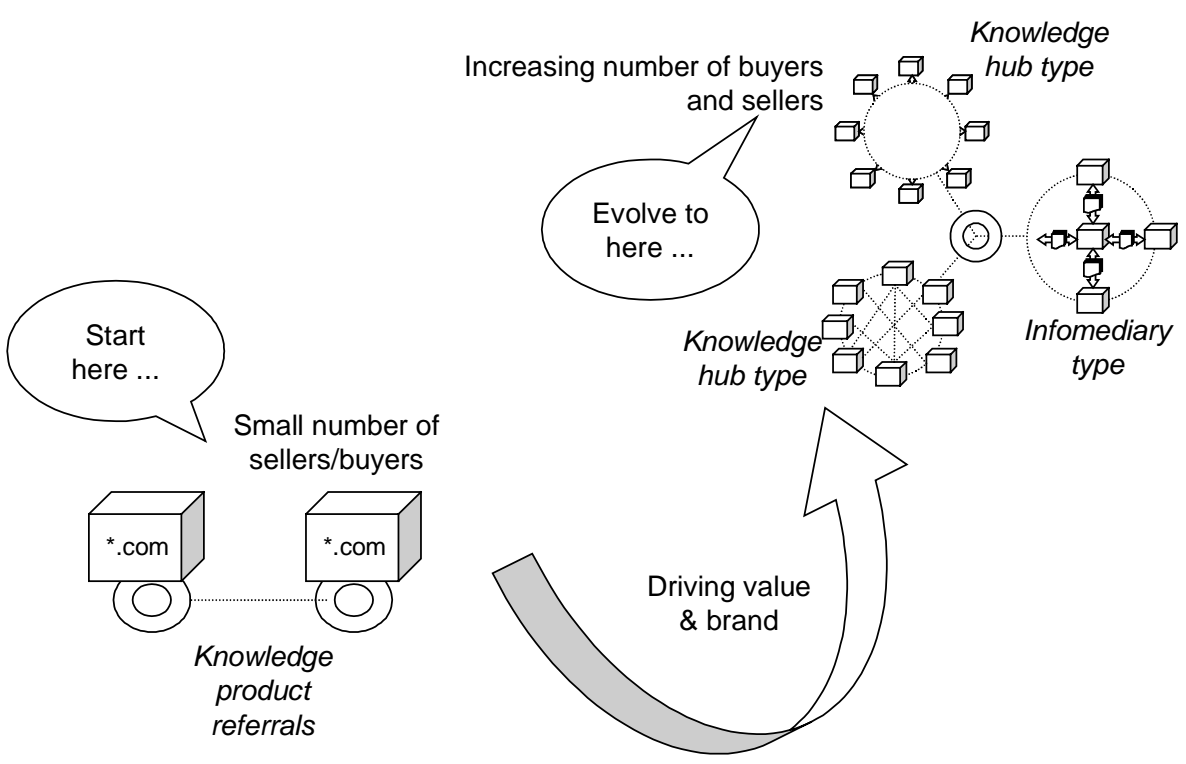

Fig. 2. Connected knowledge marketplaces

Independently of which model is followed, for effectively exploiting the network effect for conducting knowledge exchanges our analysis shows that interaction must be based on value added service, relationships must be increasingly based on trust, negotiation skills will become paramount, and there must be ample security, standards and community cohesiveness.

Value based services

The acceptance and success of knowledge marketplaces is dependent on the development and delivery of true value-added services that are offered in both digital and physical delivery systems through the evolution of trusted trading communities. The value offered by the knowledge marketplace should be greater than the traditional means of conducting the business process. We should not expect that selling knowledge assets can only be done in the digital domain, by offering only explicit knowledge. The knowledge offering should only have a tacit dimension; careful planning is needed to accommodate the selling of tacit knowledge, in terms of offering expert advice through physical (e.g. selling consulting time) or virtual (e.g. through on-line collaboration) channels.

\section{Trusted relationships}

As the critical dependency of highly customer-specific knowledge product and services increases, the need for trust and established relationships increases proportionally. For example if a company is planning to purchase some standard maintenance products, then it may be willing to try some suppliers that it has never used before. However, if a company needs expert advice on a safety-critical metal joining application that feeds the production of an aviation component, it would be most likely to rely more on trusted relationships with established knowledge providers. 
Trust is a critical component to true partnering to create long-term, knowledge intensive solution to industry pain points and to create new forms of value. It is imperative that a trust relationship be forged either through the knowledge marketplace or that established trust relationships be given a safe pathway to expand through "knowledge hubs". The trend seems (Raish, 2001) to be that independently owned and operated exchanges and e-marketplaces are the venue for transacting commodity trades that require less trust and established relationships. Industrybacked, private marketplaces on the other hand, can build on the well-established trusted relationships that exist within the existing business partnerships.

We should keep in mind that price is not the only driving factor in knowledge transactions. Factors such as quality, expertise proven in previous cases, consistency or timely delivery weigh heavily in the decision for a knowledge purchase.

Negotiation and dynamic pricing

Another key factor to consider when developing a knowledge marketplace or participating in one is the ability to buy and sell products where price and quality change with supply and demand. Negotiated pricing models include auctions, requests for quotation and exchange/matching. Negotiated commerce with multi parameter bidding allows purchases where the price is not the only driving factor, as usually is the case in knowledge transactions. Furthermore, a direct benefit of negotiated commerce is the simplification of the process to screen and select buyers. For example, a company needs a feasibility study for opening a new branch within two days. Since the company does not have the time to call each of the potential organisations that can provide this service, and does not want to award the contract to the lowest bidder automatically, a multistage, multi-parameter negotiation format may be used for the selection process. At any point, the purchaser or seller can accept, reject, or counter an offer. In the end, the negotiation process allows companies to transfer sophisticated, knowledge-intensive business transactions to the Internet.

Community cohesiveness

For knowledge marketplaces to foster a greater level of buyer loyalty and community cohesiveness they should combine the reach of the Internet with the flexibility to adapt to the changing nature of specific market needs. The real power of electronic marketplaces lies not in copying ways of working known from traditional business, but in exploiting the strength of manifold synchronous and asynchronous communication and community-building means, which is of utmost importance when dealing which such a sensible good as knowledge.

Standards

HTTP servers and XML enhanced Web content are proving effective (Ontology.org, 2002) as the foundation for small groups of co-operating commerce agents operating over the Internet. However, doubts remain whether these representations will scale to support interoperability between large, loosely coupled trading groups of buyers, sellers, brokers, aggregators and integrators, in scenarios where the full potential of the global reach of the Internet can be realised. Initiatives are already underway to agree standard XML modeling within vertical industries or markets in initiatives such as RosettaNet, CommerceNet's eCo and OASIS' ebXML.org. 


\section{Conclusions}

Within organizations, the need for continuous access to knowledge has spurred the development of various knowledge initiatives. The pervasiveness of the Internet has already started to shift existing knowledge markets into cyberspace, with examples including Intellectual property trading, copyright material, patents and designs traded online, management consultancies packaging knowledge both for internal and external use and research companies deliver much of their material over the Web. Knowledge trading refers to the trade of explicit and implicit knowledge for specific needs at an inter-organisational level. It addresses the opportunities and risks found in the purchase and selling of knowledge at the business-to-business (B2B) environment, the need for supporting long-lasting relationships of knowledge exchange and the requirement for facilitating digital community contexts where knowledge seekers can find suitable knowledge providers and knowledge providers can advertise and sell their available knowledge.

The real challenges of knowledge marketplaces lie in best exploiting the economics of knowledge. Knowledge exchanges require timeliness, trusted relationships, ability to adopt to the customer needs, to name a few. Our findings provide evidence that the most prominent model for knowledge marketplace appears to be the private one, in which organisations exploit their business partners and clients to offer highly targeted knowledge through established relations. This would potentially form a polarization between the private marketplace "clubs" and the neutral, independent knowledge marketplaces, which would be left to serve the more fragmented industry players. However, even companies that choose to build their own private knowledge marketplace will want to be connected to other knowledge networks in order to gain access to others' pools of knowledge as well as their own. Regardless of which marketplace model will prevail, knowledge marketplaces offer new means for knowledge access, delivery and application.

\section{References}

Aberdeen Group (2000) White Paper - The e-Business Marketplace: The Future of Competition. April 2000.

Bruun, P.; M. Jensen; and J. Skovgaard (2002) e-Marketplaces: Crafting a Winning Strategy, European Management Journal, article in press.

Burke, R. (1999) Integrating Knowledge-Based and Collaborative-Filtering Recommender Systems. In: AAAI-99 Workshop on Artificial Intelligence for Electronic Commerce, Orlando Florida 1999.

BuyIT (2002) e-Business Models and how they apply to you, A BuyIT Best Practice Guideline, issued by the BuyIT Best Practice Network, January 2002.

Davenport, T. and L. Prusak (1998) Working Knowledge: How Organisations Manage What They Know, Harvard Business School Press, 1998.

Davenport, T; J. Brooks; and S. Cantrell (2001) Do independent e-markets have a future? Accenture Institute for Strategic Change.

Day, Jonathan and Jim Wendler (1998) The New Economics Of Organisation, The Mckinsey Quarterly, 1998, NUMBER 119.

den Hartigh, E. and F. Langerak (2001) "Managing Increasing Returns", European Management Journal Vol. 19, No. 4, pp. 370-378, 2001. 
Dou, W. and D. Chou (2002) A Structural Analysis of Business-to-business Digital Markets, Industrial Marketing Management, 31 (2002), 165-176.

Drucker, P. (1994) Knowledge Work and Knowledge Society: The Social Transformations of this Century. Transcript of the Edw in L. Godkin Lecture delivered at Harvard University's John F. Kennedy School of Government

Drucker, P. (1997) The Future that has Already Happened, Harvard Business Review, September-October 1997.

Eisenhardt, K. M., Santos F. M. (2001) Knowledge-Based View: A New Theory of Strategy? in Pettigrew, A., Thomas, H., Whittington, R. (Eds.), Handbook of Strategy and Management, Sage Publications.

Evans, P., and T. S. Wurster (2000) Getting Real About Virtual Commerce, Harvard Business Review, Aug 1, 2000

Franke, U. (2000) The Knowledge-Based View (KBV) of the Virtual Web, the Virtual Corporation, and the Net Broker, in Y. Malhotra (ed.) Knowledge Management and Virtual Orgsanisations, Idea Group Publishing, 2000.

Gartner Group (2000) Strategic Planning, SPA-09-4188, Research Note, 8 October 2000.

Glazer, R. (1991) Marketing in an information-intensive environment: strategic implications of knowledge as an asset. Journal of Marketing 55(October), 1-19.

INKASS (2000) The INKASS Project Web Site, www.incass.com (1 August 2002)

Kaplan, S. and M. Sawhney (2000) E-hubs: The New B2B Marketplaces, Harvard Business Review, May-June 2000.

McGuiness, D.L. (1999) Ontologies for Electronic Commerce. In: AAAI-99 Workshop on Artificial Intelligence for Electronic Commerce, Orlando Florida 1999.

Nohr, Holger; Roos, Alexander W. (2001) Informationsqualität als Instrument des Wissensmanagements. In: Wissensmanagement 3 (2001) 2, S. 24-27

Ontology.org (2002) The need for shared ontology, white paper, www.ontology.org (1 August 2002)

O'Hara, K., Nigel R. Shadbolt (2001) Issues for an Ontology for Knowledge Valuation. In Proceedings of the IJCAI'01 Workshop on E-Business and the Intelligent Web, Seattle, WA, USA, August 2001.

Raisch, W. D. (2001) 'The E-Marketplace Strategies for Success in B2B eCommerce', McGraw-Hill.

Rolph, Paul; Bartram, Peter (1994) The Information Agenda: Harnessing Relevant Information in a Changing Business Environment. London: Management Books 2000, 1994

Skyrme, D. J. (2001) "Capitalizing on Knowledge: From e-business to k-business", Butterworth-Heinemann, London.

Whittle, R. (1997) The Evolution of Ernie - The online Business Consultant, Marshall School of Business, University of Southern California 